\title{
$\alpha$-Tocopherol transfer protein mediates protective hypercapnia in murine ventilator-induced lung injury
}

\author{
Gail Otulakowski, ${ }^{1}$ Doreen Engelberts, ${ }^{1}$ Hajime Arima, ${ }^{1,2,3}$ Hiroyuki Hirate, ${ }^{1,2,3}$ \\ Hülya Bayir, ${ }^{4,5}$ Martin Post, ${ }^{1}$ Brian P Kavanagh ${ }^{1,2,6}$
}

\begin{abstract}
- Additional material is
published online only. To view please visit the journal online (http://dx.doi.org/10.1136 thoraxjn-2016-209501)
\end{abstract}

'Physiology and Experimental Medicine, Hospital for Sick Children, Toronto, Canada 2Department of Critical Care Medicine, Hospital for Sick Children, Toronto, Canada ${ }^{3}$ Department of Anesthesiology and Intensive Care Medicine

Nagoya City University Graduate School of Medical Sciences,

Nagoya, Japan

${ }^{4}$ Department of Environmental and Occupational Health, Center for Free Radical and Antioxidant Health, University of Pittsburgh, Pittsburgh, Pennsylvania, USA ${ }^{5}$ Department of Critical Care Medicine, Safar Center for Resuscitation Research, University of Pittsburgh Pittsburgh, Pennsylvania, USA ${ }^{6}$ Department of Anesthesia, University of Toronto, Toronto, Canada

Correspondence to Dr Brian P Kavanagh, Department of Critical Care Medicine, Hospital for Sick Children, 555 University Avenue, Toronto, Ontario, Canada M5G 1X8; brian.kavanagh@utoronto. ca

Received 28 September 2016 Revised 6 January 2017 Accepted 9 January 2017 Published Online First 3 February 2017

\section{ABSTRACT}

Rationale Hypercapnia is common in mechanically ventilated patients. Experimentally, 'therapeutic hypercapnia' can protect, but it can also cause harm, depending on the mechanism of injury. Hypercapnia suppresses multiple signalling pathways. Previous investigations have examined mechanisms that were known a priori, but only a limited number of pathways, each suppressed by $\mathrm{CO}_{2}$, have been reported.

Objective Because of the complexity and interdependence of processes in acute lung injury, this study sought to fill in knowledge gaps using an unbiased screen, aiming to identify a specifically upregulated pathway.

Methods and results Using genome-wide gene expression analysis in a mouse model of ventilatorinduced lung injury, we discovered a previously unsuspected mechanism by which $\mathrm{CO}_{2}$ can protect against injury: induction of the transporter protein for $\alpha$-tocopherol, $\alpha$-tocopherol transfer protein ( $\alpha \mathrm{TTP})$. Pulmonary $\alpha$ TTP was induced by inspired $\mathrm{CO}_{2}$ in two in vivo murine models of ventilator-induced lung injury; the level of $\alpha$ TTP expression correlated with degree of lung protection; and, absence of the $\alpha$ TTP gene significantly reduced the protective effects of $\mathrm{CO}_{2} . \alpha$-Tocopherol is a potent antioxidant and hypercapnia increased lung $\alpha$-tocopherol in wild-type mice, but this did not alter superoxide generation or expression of NRF2-dependent antioxidant response genes in wild-type or in $\alpha \mathrm{TTP}^{-1-}$ mice. In concordance with a regulatory role for $\alpha$-tocopherol in lipid mediator synthesis, hypercapnia attenuated 5-lipoxygenase activity and this was dependent on the presence of $\alpha$ TTP.

Conclusions Inspired $\mathrm{CO}_{2}$ upregulates $\alpha$ TTP which increases lung $\alpha$-tocopherol levels and inhibits synthesis of a pathogenic chemoattractant.

\section{INTRODUCTION}

Hypercapnia is common in mechanically ventilated patients with injured lungs, where tidal volume is deliberately lowered to lessen the risk of ventilatorinduced lung injury (VILI). ${ }^{1}$ However, accumulating evidence indicates that $\mathrm{CO}_{2}$ can have potent effects in injured tissue that are independent of changes in mechanical ventilation. ${ }^{2}$ Depending on the context, these effects may be protective, for example, attenuating reperfusion injury, ${ }^{3}$ acute sepsis ${ }^{4}$ or ventilator-induced injury; ${ }^{5}$ or, injurious, for example, impairing alveolar fluid clearance. ${ }^{7}$

Several molecular mechanisms of hypercapnic action have been described. For example,

\section{Key messages}

What is the key question?

- Can molecular mechanisms induced by hypercapnia during mechanical ventilation reveal potential therapeutic pathways for lung injury?

- Does hypercapnia protect against lung injury by activating protective genes?

What is the bottom line?

- Inspired $\mathrm{CO}_{2}$ upregulates a transport protein ( $\alpha$-tocopherol transfer protein); this mobilises vitamin $E$ in the lung which inhibits synthesis of a pathogenic chemoattractant, leukotriene B4.

\section{Why read on?}

- Experimental elevation of $\mathrm{CO}_{2}$ can protect (or cause harm); this new induced mechanism of protection from $\mathrm{CO}_{2}$ provides new potentially testable therapies for lung injury.

elevated $\mathrm{CO}_{2}$ inhibits expression of inflammatory cytokines, ${ }^{5}$ activation of nuclear factor $\kappa B$ $(\mathrm{NF \kappa B})^{8}$ and sheddase (a disintegrin and metalloprotease 17; ADAM17) ${ }^{6}$ signalling, and functional protein expression (eg, endocytosis of ion channels). ${ }^{7}$ However, these observations are limited in scope because all were based on injury processes known a priori. Also, many of the mechanisms are pivotal biological processes and thus have limited translational potential (eg, inhibition of $\mathrm{NF \kappa B}$ ).

We sought to address this knowledge gap using an unbiased screen. We chose a microarray approach because the technology is mature, and because regulation at the level of gene expression would be a proximal and fundamental step in most identified signalling or synthetic processes. Microarray analyses have led to identification of key molecular pathways in VILI $^{9}$ and of genes regulated by hypercapnia in neonatal lung development, ${ }^{10}$ and provide the possibility of identifying a specifically upregulated mechanistic pathway. Hypercapnia-dependent transcriptional responses have been recently reviewed. ${ }^{11}$ While not fully characterised, they include inhibition of $\mathrm{NF \kappa B}^{12}$ and hypoxia-inducible factor $1 \alpha(\mathrm{HIF}-1 \alpha)^{13}$ responses, and activation of CREB $^{14}$ and FoxO3a. ${ }^{15}$ 
We utilised a mouse model of VILI in which addition of $\mathrm{CO}_{2}$ to the inspired gas protects against injury. ${ }^{5}$ We found that hypercapnia activated few genes; however, hypercapnia was protective in VILI, and here it increased the expression of $\alpha$-tocopherol transfer protein $(\alpha \mathrm{TTP})$. We describe how increased expression of $\alpha$ TTP may contribute to the protection afforded by hypercapnia in this multifaceted in vivo model.

\section{METHODS}

Additional details can be found in the online supplementary data.

\section{Animal model}

All animal procedures were approved by the animal care committee of the Hospital for Sick Children (Toronto, Ontario, Canada) in accordance with the Guidelines of the Canadian Council on Animal Care. C57BL/6J male mice (20-25 g, Charles River, St Constant, Quebec, Canada) were anesthetised and ventilated: tidal volume $\left(\mathrm{V}_{\mathrm{T}}\right) 10 \mathrm{~mL} / \mathrm{kg}$, positive end-expiratory pressure (PEEP) $2.0 \mathrm{~cm} \mathrm{H}_{2} \mathrm{O}$, frequency 135 / min, $\mathrm{FiO}_{2}$ 0.21. Two models were employed. Model-1: mice were randomised to Severe Injury as previously described ${ }^{5}$ (peak inspiratory pressure $27 \mathrm{~cm} \mathrm{H}_{2} \mathrm{O}, \mathrm{V}_{\mathrm{T}} 35-40 \mathrm{~mL} / \mathrm{kg}$, PEEP $0 \mathrm{~cm} \mathrm{H}_{2} \mathrm{O}$, frequency $30-35 / \mathrm{min}$ ) versus continuation of baseline (low $\mathrm{V}_{\mathrm{T}}$ ) ventilation with normocapnia $\left(\mathrm{FiO}_{2} \quad 0.75, \mathrm{FiCO}_{2}\right.$ 0 , balance $\left.\mathrm{N}_{2}\right)$ or hypercapnia $\left(\mathrm{FiO}_{2} 0.75, \mathrm{FiCO}_{2} 0.12\right.$, balance $\mathrm{N}_{2}$ ) for 3 hours. Model-2: mice were subjected to Moderate Injury $\left(\mathrm{V}_{\mathrm{T}} 20 \mathrm{~mL} / \mathrm{kg}\right.$, PEEP $0 \mathrm{~cm} \mathrm{H}_{2} \mathrm{O}$, frequency $\left.45 / \mathrm{min}\right)$ for 4 hours, randomised to normocapnia (room air) or hypercapnia $\left(\mathrm{FiCO}_{2}\right.$ 0.12, balance room air).

\section{Genetically modified mice}

Male knockout $\left(\alpha \mathrm{TTP}^{-/-}\right.$) (strain B6.129S4-Ttpa ${ }^{1 \mathrm{Far}} / \mathrm{J}$, Jackson Laboratories, Sacramento, California, USA) and wild-type sibling $\left(\alpha \mathrm{TTP}^{+/+}\right)$controls were subjected to severe injury (Model-1) and randomised to normocapnia or hypercapnia.

\section{Microarray analysis}

We performed gene expression analysis using lung samples from mice included in our previous study, ${ }^{6}$ ventilated with the Severe Injury protocol (Model-1). RNA from five groups: (1) nonventilated, (2) low $\mathrm{V}_{\mathrm{T}}$ normocapnia, (3) low $\mathrm{V}_{\mathrm{T}}$ hypercapnia, (4) high $\mathrm{V}_{\mathrm{T}}$ normocapnia, and (5) high $\mathrm{V}_{\mathrm{T}}$ hypercapnia $(\mathrm{n}=5 /$ group non-ventilated and low $\mathrm{V}_{\mathrm{T}} ; \mathrm{n}=10$ /group high $\mathrm{V}_{\mathrm{T}}$ ) was hybridised to Affymetrix (Santa Clara, California, USA) mouse gene 1.0 ST arrays. Primary datasets are accessible through NCBI GEO (series accession number GSE86229). Data were subjected to robust multichip analysis normalisation; preliminary principal components analysis (PCA) identified two outliers which were subsequently excluded from downstream analysis. Analysis of changes in gene expression was performed using Partek Genomics Suite (Partek Inc, St Louis, Michigan, USA), by two-way analysis of variance (ANOVA) using ventilation (nonventilated, high $\mathrm{V}_{\mathrm{T}}$, low $\mathrm{V}_{\mathrm{T}}$ ) and $\mathrm{CO}_{2}$ (normocapnia, hypercapnia) as factors, Benjamini and Hochberg false discovery rate 5\%, and fold-change cutoff at 1.5. Overrepresented canonical pathways associated with $\mathrm{V}_{\mathrm{T}}$ and hypercapnia were identified using Ingenuity Pathway Analysis (IPA, Ingenuity Systems, Redwood City, California, USA).

\section{RT-PCR}

Changes in gene expression were measured using relative quantitative real-time PCR by the ddCt method. Primers are shown in online supplementary table $\mathrm{S} 1$.

\section{Inflammatory mediators}

Myeloperoxidase (MPO) was measured in lung homogenates using $\mathrm{O}$-dianisidine dihydrochloride and $\mathrm{H}_{2} \mathrm{O}_{2}$ as substrates. Cytokines in bronchoalveolar (BAL) fluid were quantitated using a Milliplex mouse Cytokine Immunoassay Kit (Millipore, Billerica, Massachusetts, USA). Eicosanoids in BAL were quantitated by liquid chromatography (LC)-tandem mass spectrometry (MS), with cysteinyl leukotrienes (CysLTs) measured by enzyme immunoassay (Enzo Life Sciences, Farmingdale, New York, USA). Superoxide radical in hydroethidine-treated mouse lung was detected through quantification of 2-hydroxyethidium using LC-MS-MS analysis.

\section{Lung tissue $\boldsymbol{\alpha}$-tocopherol}

Lung tissue $\alpha$-tocopherol was quantitated using HPLC from homogenates spiked with internal standard $\delta$-tocopherol (Sigma-Aldrich Canada Co., Oakville, Ontario, Canada).

\section{Statistics}

Data are presented as dot plots with mean (for normally distributed data) or median (non-normal distributions) indicated by a horizontal bar. Statistical analyses were calculated with Sigmaplot V.12.3 (Systat software Inc) using ANOVA for multigroup comparisons. Two group comparisons used t tests on normally distributed data, and Mann-Whitney U for non-normally distributed data. $\mathrm{p}$ values $<0.05$ were considered significant.

\section{RESULTS}

\section{Gene expression and hypercapnic protection against} ventilator-induced lung injury

High $\mathrm{V}_{\mathrm{T}}$ ventilation was used to generate VILI in C57BL/6J mice, as previously published; ${ }^{6} \mathrm{CO}_{2}$ (hypercapnia) was added to the inspired gas to protect against VILI in two of five experimental groups: (1) non-ventilated, (2) low $\mathrm{V}_{\mathrm{T}}$ normocapnia, (3) low $\mathrm{V}_{\mathrm{T}}$ hypercapnia, (4) high $\mathrm{V}_{\mathrm{T}}$ normocapnia, and (5) high $\mathrm{V}_{\mathrm{T}}$ hypercapnia. ${ }^{6}$ Lung injury was significantly greater in high $\mathrm{V}_{\mathrm{T}}$ normocapnia compared with all other groups, and hypercapnia protected against VILI. ${ }^{6} \mathrm{PaO}_{2}, \mathrm{PaCO}_{2}$ and $\mathrm{pH}$ values are given in online supplementary table S2.

Microarray analysis of lung samples was used to determine gene expression patterns associated with hypercapnic protection. PCA confirmed that whole gene expression profiles were similar among samples within each group (figure 1A). Two-way ANOVA analysis of overall gene expression with ventilation and $\mathrm{CO}_{2}$ as factors both showed significant sources of variation, but no significant interaction (figure $1 \mathrm{~B}$ ). High $\mathrm{V}_{\mathrm{T}}$ ventilation (normocapnia) changed the expression of 1658 gene probe sets (contrasted with no ventilation or low $\mathrm{V}_{\mathrm{T}}$; fold change 1.5 , $\mathrm{p}<0.05$ ), including large increases in inflammatory gene expression (see online supplementary table S3).

In high $\mathrm{V}_{\mathrm{T}}$ ventilation, there were modest changes in gene expression when contrasting normocapnia with hypercapnia. Hierarchical clustering of this gene set (figure 1C) confirmed distinct expression patterns, with some overlap in low $\mathrm{V}_{\mathrm{T}}$ (uninjured) ventilation. A small number of genes were overexpressed in high $\mathrm{V}_{\mathrm{T}}$ hypercapnia versus high $\mathrm{V}_{\mathrm{T}}$ normocapnia, and most differentially expressed genes displayed downregulation under hypercapnia. Twenty-nine independent known genes responding to hypercapnia during high $\mathrm{V}_{\mathrm{T}}$ ventilation were identified (table 1). We selected 12 candidate genes from this list based on plausibly protective effect and regulation at the transcriptional level, and real time RT-PCR confirmed that nine were regulated by hypercapnia (gene symbols: Ttpa, Pmvk, Pdgfb, Ereg, Egr2, 
A

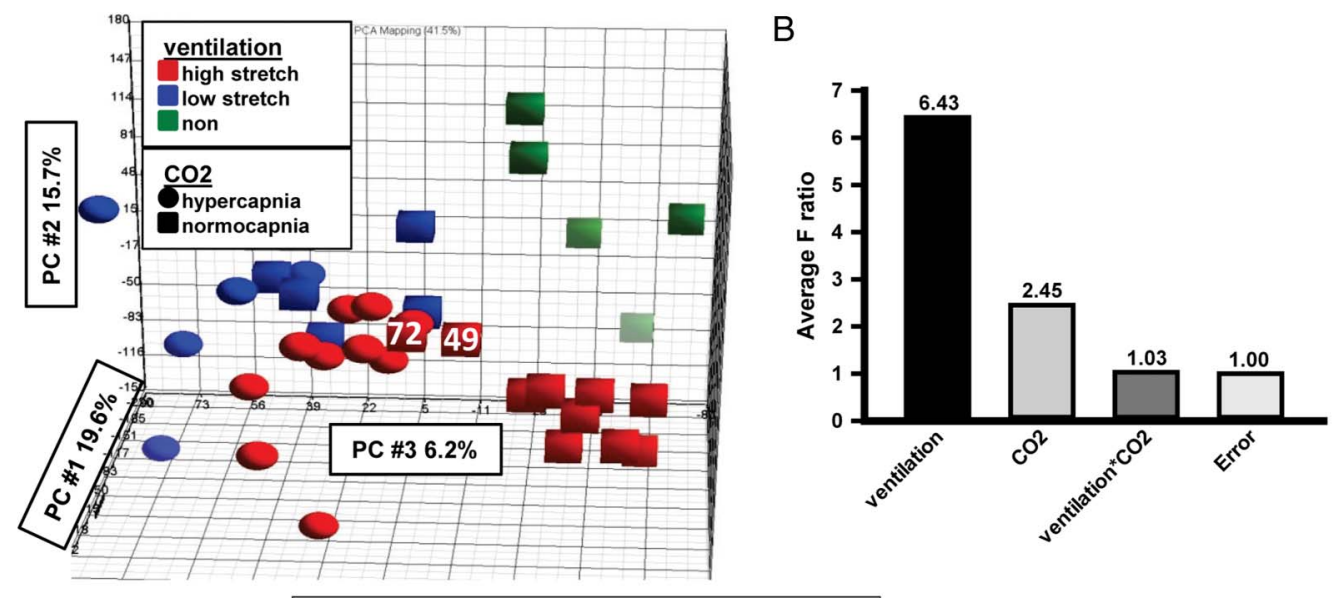

C

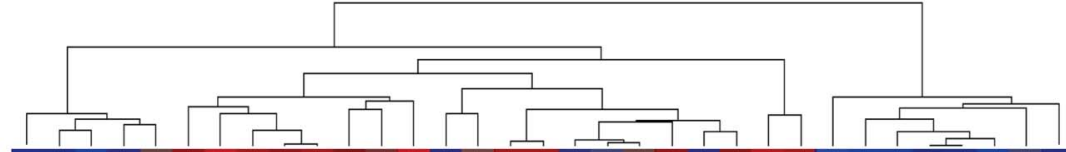

Figure 1 Microarray data in murine ventilator-induced lung injury and hypercapnia. (A) Principal component analysis plot for microarray data showing effects of ventilation and hypercapnia. Note: samples 72 and 49, from the high stretch normocapnia group, fell closer to the high stretch hypercapnia cluster than the high stretch normocapnia cluster and were excluded from further analysis. (B) Sources of variation in total gene expression estimated by two-way ANOVA. F ratio (y-axis) for each factor ( $\mathrm{x}$-axis) represents the F-statistics for that factor relative to F-statistic for error (noise) for all genes. (C) Cluster analysis showing changes in mRNA abundance during mouse lung ventilation as determined by microarray analysis. Each column represents RNA from a single mouse, and the heatmap shows genes detected by Robust Multichip Average analysis with expression increased (red) or decreased (blue) by 1.5 fold. HS, high stretch; LS, low stretch; HC, hypercapnia; NC, normocapnia; NV, non-ventilated.

Tnc, Gsta1, Ncr1 and Hmox1); three trended as in microarrays, but were not significant (P2ry10, Cckar, Ctgf; table 1).

\section{Identification of candidate gene $\alpha$ TTP in VILI}

The most highly upregulated gene, encoding $\alpha$ TTP, was significantly more expressed in high $\mathrm{V}_{\mathrm{T}}$ hypercapnia versus high $\mathrm{V}_{\mathrm{T}}$ normocapnia (confirmed by RT-PCR; table 1). In addition, the degree of protection (eg, decrement in static compliance) from hypercapnia was proportional to the degree of expression of the $\alpha$ TTP mRNA (figure 2). We used a second model of more moderate ventilation injury $\left(\mathrm{V}_{\mathrm{T}}=20 \mathrm{~mL} / \mathrm{kg} ; \mathrm{FiO}_{2}=0.21\right.$; see online supplementary figure S1), in which hypercapnia attenuated 
Table 1 List of genes differentially expressed by hypercapnia in severe injury VILI

\begin{tabular}{|c|c|c|c|c|c|}
\hline \multirow[b]{2}{*}{ Symbol } & \multirow[b]{2}{*}{ Gene } & \multicolumn{2}{|c|}{ Expression change by microarray } & \multicolumn{2}{|c|}{$\begin{array}{l}\text { Expression by RTPCR } \\
\text { (relative to NV; mean } \\
\pm \text { SEM) }\end{array}$} \\
\hline & & p Value* (hyper vs normo) & Fold change (hyper vs normo) & Normo & Hyper \\
\hline Ttpa & $\alpha$-tocopherol transfer protein & 7.99E-07 & 1.74 & $0.94 \pm 0.12$ & $2.11 \pm 0.42 \dagger$ \\
\hline Tat & tyrosine aminotransferase & $8.56 \mathrm{E}-04$ & 1.71 & not tested & \\
\hline Pmvk & phosphomevalonate kinase & $3.80 \mathrm{E}-05$ & 1.66 & $4.70 \pm 0.70$ & $8.50 \pm 1.20 \ddagger$ \\
\hline P2ry10 & purinergic receptor P2Y, G-protein coupled 10 & $2.33 \mathrm{E}-03$ & 1.55 & $1.60 \pm 0.16$ & $3.04 \pm 0.88$ \\
\hline Fat3 & FAT tumour suppressor homologue 3 (Drosophila) & $5.31 \mathrm{E}-05$ & 1.53 & not tested & \\
\hline Zc3h6 & zinc finger $\mathrm{CCCH}$ type containing 6 & $1.56 \mathrm{E}-05$ & 1.53 & not tested & \\
\hline Cckar & cholecystokinin A receptor & $2.78 \mathrm{E}-04$ & 1.52 & $0.32 \pm 0.03$ & $0.48 \pm 0.06$ \\
\hline Plcxd3 & phosphatidylinositol-specific phospholipase $C, X$ domain C & $3.35 \mathrm{E}-08$ & 1.50 & not tested & \\
\hline Gsta2 & glutathione S-transferase, $\alpha 2$ (Yc2) & $1.30 \mathrm{E}-05$ & -1.50 & not tested & \\
\hline Ctps & cytidine $5^{\prime}$-triphosphate synthase & $3.89 \mathrm{E}-07$ & -1.52 & not tested & \\
\hline Pus기 & pseudouridylate synthase 7 homologue (S. cerevisiae)-like & 3.67E-06 & -1.52 & not tested & \\
\hline Pdgfb & platelet-derived growth factor, B polypeptide & $8.12 \mathrm{E}-06$ & -1.56 & $1.08 \pm 0.10$ & $0.55 \pm 0.06 \dagger$ \\
\hline Scel & sciellin & $1.16 \mathrm{E}-03$ & -1.58 & not tested & \\
\hline $\operatorname{Sh} 2 d 4 a$ & SH2 domain containing $4 \mathrm{~A}$ & $1.80 \mathrm{E}-09$ & -1.58 & not tested & \\
\hline Ereg & epiregulin & $8.22 \mathrm{E}-07$ & -1.59 & $5.82 \pm 0.95$ & $2.27 \pm 0.27 \ddagger$ \\
\hline Egr2 & early growth response 2 & $1.43 \mathrm{E}-04$ & -1.60 & $9.21 \pm 1.80$ & $4.23 \pm 0.57 \ddagger$ \\
\hline Tnc & tenascin C & $2.94 \mathrm{E}-04$ & -1.61 & $4.21 \pm 1.01$ & $1.60 \pm 0.28 \ddagger$ \\
\hline Gsta1 & glutathione S-transferase, $\alpha 1$ (Ya) & $1.71 \mathrm{E}-05$ & -1.62 & $6.91 \pm 1.33$ & $2.58 \pm 0.45 \dagger$ \\
\hline Rnd1 & Rho family GTPase 1 & $1.74 \mathrm{E}-04$ & -1.63 & not tested & \\
\hline Mthfd2 & methylenetetrahydrofolate dehydrogenase & $2.44 \mathrm{E}-05$ & -1.64 & not tested & \\
\hline $\mathrm{Ccl} 7$ & chemokine (C-C motif) ligand 7 & $1.26 \mathrm{E}-06$ & -1.65 & not tested & \\
\hline Ctgf & connective tissue growth factor & $1.39 \mathrm{E}-04$ & -1.67 & $3.95 \pm 0.822$ & $1.95 \pm 0.42$ \\
\hline S/c26a4 & solute carrier family 26 , member 4 & $9.52 \mathrm{E}-06$ & -1.75 & not tested & \\
\hline Timp1 & tissue inhibitor of metalloproteinase 1 & $5.00 \mathrm{E}-05$ & -1.82 & not tested & \\
\hline Ner1 & natural cytotoxicity triggering receptor 1 & $5.82 \mathrm{E}-07$ & -1.82 & $0.65 \pm 0.07$ & $0.26 \pm 0.03 \dagger$ \\
\hline Cxcl5 & chemokine (C-X-C motif) ligand 5 & 7.43E-05 & -1.88 & not tested & \\
\hline Spic & Spi-C transcription factor (Spi-1/PU.1 related) & $1.07 \mathrm{E}-03$ & -1.96 & not tested & \\
\hline Hmox1 & heme oxygenase (decycling) 1 & $6.72 \mathrm{E}-05$ & -1.98 & $12.9 \pm 1.99$ & $4.51 \pm 0.59$ \\
\hline $\mathrm{CCl} 2$ & chemokine (C-C motif) ligand 2 & $2.16 \mathrm{E}-06$ & -2.05 & not tested & \\
\hline
\end{tabular}

injury (ie, BAL protein, lung MPO), and induced $\alpha$ TTP mRNA (figure 3).

The top canonical pathways associated with gene expression from high $\mathrm{V}_{\mathrm{T}}$ (figure $4 \mathrm{~A}$ ) included inflammation-related signalling pathways known to be associated with VILI (NFkB, IL-6, p38 MAPK, HMGB1). A single pathway, the NRF2-mediated oxidative stress response, was shared by high $\mathrm{V}_{\mathrm{T}}$ and by hypercapnia (figure 4B); this is a protective response against oxidative and xenobiotic toxicity, and potentially against VILI. ${ }^{16}$ High $\mathrm{V}_{\mathrm{T}}$ increased expression of NRF2 target genes, but these were decreased (not further increased) with hypercapnia (figure 5).

$\alpha \mathrm{TTP}$, the most upregulated gene, is a cytosolic protein that shuttles $\alpha$-tocopherol (vitamin E), an important antioxidant, between cellular membranes. We hypothesised that increased $\alpha$ TTP expression in hypercapnia provides antioxidant protection upstream of the antioxidant NRF2 pathway, thereby limiting its induction.

$\alpha$ TTP gene deletion: impact on protection from $\mathrm{CO}_{2}$

To examine the role of $\alpha$ TTP in hypercapnia-mediated protection from VILI, we used knockout $\left(\alpha \mathrm{TTP}^{-/-}\right)$and wild-type

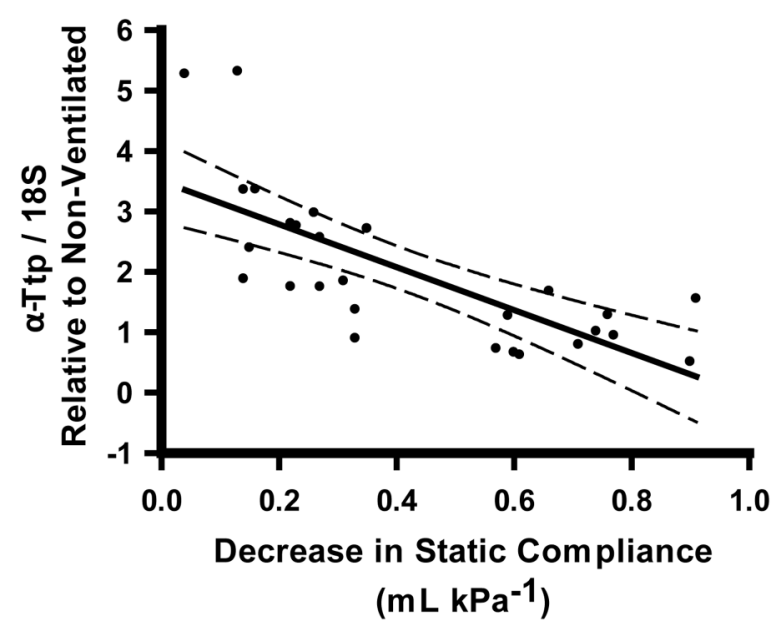

Figure 2 Hypercapnic protection and expression of $\alpha$-tocopherol transferase protein $(\alpha T T P)$. Linear regression analysis indicating correlation between $\alpha$ TTP mRNA expression (RT-PCR) and decrease in static compliance in ventilated mice. Dotted lines indicate $95 \% \mathrm{Cls}$. $\mathrm{R}=-0.73, \mathrm{p}<0.001$. 

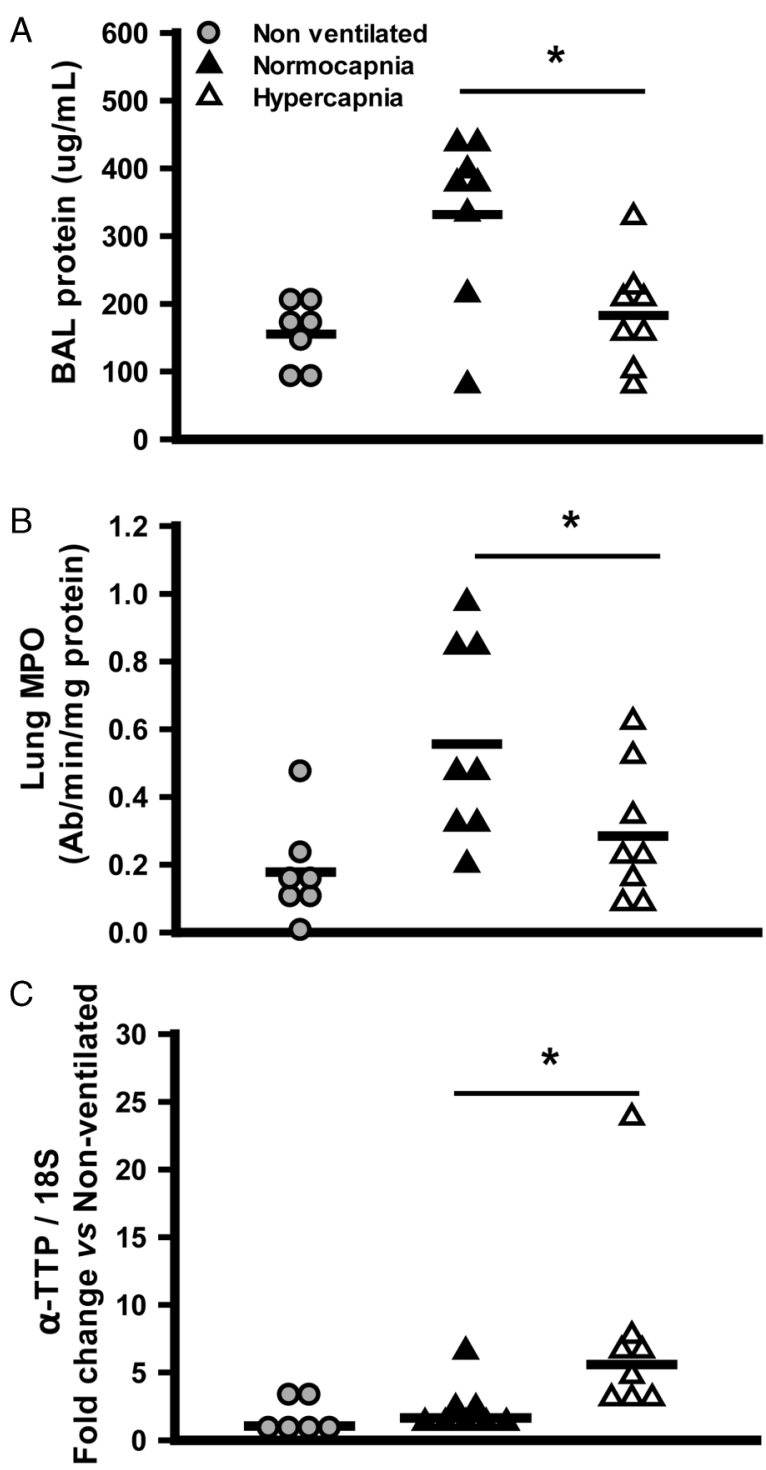

Figure 3 Hypercapnic protection and expression of $\alpha$-tocopherol transferase protein ( $\alpha$ TTP) in milder injury. Hypercapnia reduced protein concentration in the bronchoalveolar lavage (BAL) fluid (A), lung tissue myeloperoxidase (MPO) activity (B), and increased the tissue expression of $\alpha$ TTP mRNA (C), in a model of milder ventilator-induced lung injury (4 hours, $V_{T}=20 \mathrm{~mL} / \mathrm{kg}$ ) ( ${ }^{*} p<0.05$ vs normocapnia, $t$ test). Data from small numbers of non-ventilated mice are presented for illustrative purposes but excluded from statistical analysis.

sibling $\left(\alpha \mathrm{TTP}^{+/+}\right)$mice subjected to high $\mathrm{V}_{\mathrm{T}}$ ventilation. All mice had similar lung compliance at baseline, and similar decreases in compliance over 3 hours during high $\mathrm{V}_{\mathrm{T}}$ ventilation with normocapnia (see online supplementary figure S2A). Hypercapnia attenuated several markers of injury in $\alpha \mathrm{TTP}^{+/+}$ but not $\alpha \mathrm{TTP}^{-/-}$mice: compliance (figure $6 \mathrm{~A}, \mathrm{~B}$ ), lung tissue $\mathrm{MPO}$ and TNF $\alpha$ mRNA (figure 7A, B), and BAL levels of MCP-1 and KC (figure 7C, D). Also, hypercapnia tended to decrease BAL IL-6 in $\alpha \mathrm{TTP}^{+/+}$mice only (figure $7 \mathrm{E}$ ).

\section{Role of $\alpha$ TTP and $\alpha$-tocopherol in protection with} hypercapnia

Hypercapnia induced lung tissue expression of $\alpha$ TTP mRNA in $\alpha \mathrm{TTP}^{+/+}$sibs (figure $8 \mathrm{~A}$ ) following high $\mathrm{V}_{\mathrm{T}}$ ventilation, and greater expression of $\alpha \mathrm{TTP}$ mRNA was associated with greater protection (figure $8 \mathrm{~B}$ ) (as with C57BL/6J mice: table 1, figure 2). In addition, lung tissue $\alpha$-tocopherol levels were increased by hypercapnia during high $\mathrm{V}_{\mathrm{T}}$ ventilation in $\alpha \mathrm{TTP}^{+/+}$sibs (figure $8 \mathrm{C}$ ), while in $\alpha \mathrm{TTP}^{-/-}$sibs, levels were $20-50$ fold less and were not altered by ventilation (figure $8 \mathrm{D}$ ).

$\boldsymbol{\alpha}$-Tocopherol and oxidative stress in ventilator-induced lung injury

The decrease in NRF2 target gene expression due to hypercapnia in the $\mathrm{C} 57 \mathrm{BL} / 6 \mathrm{~J}$ mice (figure $4 \mathrm{~B}$ ) suggested that hypercapnic induction of $\alpha$ TTP may exert antioxidant effects by shuttling $\alpha$-tocopherol; reduced oxidative stress would then explain the lessened induction of NRF2 target gene expression. If this were true, then in the setting of lung injury, hypercapnia should lower the expression of NRF2 target genes in $\alpha \mathrm{TTP}^{+/+}$sibs, but not in $\alpha \mathrm{TTP}^{-/-}$mice. Constitutive expression of HMOX1 and GSTA1 was highest in lungs of $\alpha \mathrm{TTP}^{-/-}$(vs $\alpha \mathrm{TTP}^{+/+}$) and lowest in $\mathrm{C} 57 \mathrm{BL} / 6 \mathrm{~J}$ mice (figure 9A, B), perhaps an adaption to low $\alpha$-tocopherol levels. However, $\alpha \mathrm{TTP}^{-/-}$and $\alpha \mathrm{TTP}^{+/+}$mice showed similar changes in HMOX1 and GSTA1 in response to ventilation and hypercapnia (figure 9C, D), indicating that these effects are independent of $\alpha$ TTP expression.

To determine whether $\alpha$ TTP protected via an antioxidant mechanism, we measured 2-hydroxyethidium as a unique marker of superoxide generation in mice injected with hydroethidine; hypercapnia had no impact on $\alpha \mathrm{TTP}^{-/-}$or $\alpha \mathrm{TTP}^{+/+}$ mice (figure 10A). Similar results were found using multiple markers of oxidative stress (eg, 8-isoprostane, protein carbonyls, and antioxidant capacity assay: data not shown).

\section{$\alpha$-Tocopherol and eicosanoids in lung injury}

$\alpha$-Tocopherol inhibits 5-lipoxygenase (5-LOX) ${ }^{17}$ and its downstream products, the leukotriene B4 (LTB4) and cysteinyl leukotrienes (CysLTs: LTC4, LTD4 and LTE4), are pathogenic in lung injury and ARDS. ${ }^{18}$ Hypercapnia suppressed the BAL level of LTB4 and CysLTs in $\alpha \mathrm{TTP}^{+/+}$, but not in $\alpha \mathrm{TTP}^{-/-}$, mice (figure 10B, C). A similar trend was observed for the additional 5-LOX product 5-hydroxyeicosatetraenoic acid (5-HETE) (see online supplementary table S4). There were no differences in levels of the eicosanoid precursor arachidonic acid (figure 10D), or in other downstream products (eg, HETEs, prostaglandins or epoxyeicosatrienoic acids) (see online supplementary table S4).

\section{DISCUSSION}

The current study provides evidence of a previously unsuspected mechanism by which $\mathrm{CO}_{2}$ can protect against lung injury: induction of a transporter protein for $\alpha$-tocopherol, $\alpha$ TTP. Addition of $\mathrm{CO}_{2}$ to the inspired gas increased pulmonary expression of $\alpha \mathrm{TTP}$ mRNA in different in vivo murine models of VILI; the level $\alpha$ TTP expression correlated with degree of lung protection; and, absence of the $\alpha$ TTP gene abolished the protective effects of $\mathrm{CO}_{2}$. These data provide new insights into the mechanisms of action of $\mathrm{CO}_{2}$ on molecular pathways in lung injury beyond previously described multifactorial inhibitory effects such as $\mathrm{NF \kappa B},{ }^{8}$ ADAM $17^{6}$ and Na,K-ATPase. ${ }^{7}$ In contrast to previously described mechanisms, the current data demonstrate that $\mathrm{CO}_{2}$ upregulates expression of $\alpha \mathrm{TTP}$, which increases lung $\alpha$-tocopherol levels; $\alpha$-tocopherol can inhibit synthesis of the inflammatory mediator leukotrienes, products of 5 -LOX which are pathogenic in acute lung injury. ${ }^{18}$

Although $\alpha$ TTP was required for hypercapnia's protective effects, we did not find that $\alpha$ TTP knockout (KO) mice injured more readily than wild-type mice in normocapnic conditions; in fact, the opposite may be true, since the decrease in static 
Figure 4 Top canonical pathways in response to mechanical ventilation. Differences in mRNAs in lungs of non-ventilated and ventilated mice were identified through microarray analysis and submitted to functional enrichment analysis using Ingenuity Pathway Analysis. Highly significant genes were selected by Fisher's exact test (at $p<0.0001$ ), and the statistical significance of each pathway is presented as negative log ( $p$ value). Pathways associated with genes affected by stretch (A) or associated with genes affected by hypercapnia (B) are illustrated.

A

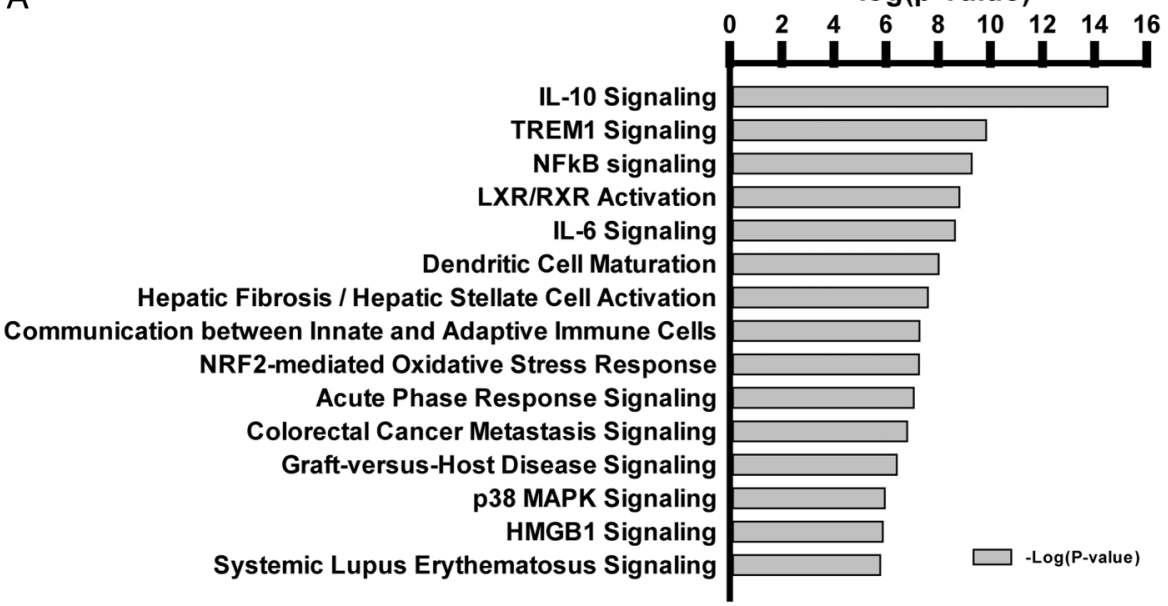

B
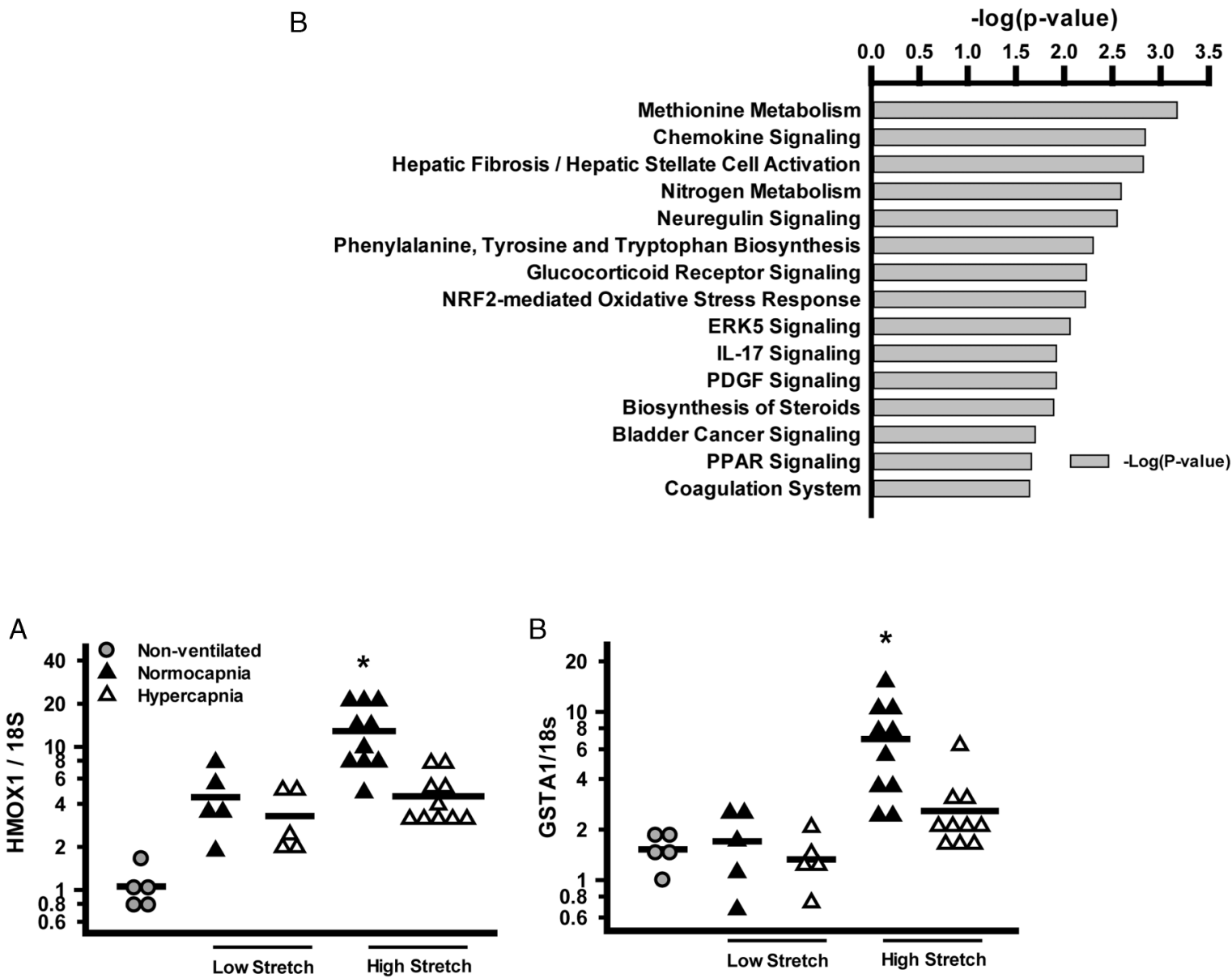

Figure 5 Relative expression of mRNAs of the antioxidant response pathway in lungs of mechanically ventilated mice. NRF2 target genes heme oxygenase (HMOX1; A) and glutathione-S-transferase (GSTA1; B) were more highly expressed in high stretch normocapnia than all other ventilated groups; that is, addition of hypercapnia reduced the expression of each during high stretch ventilation ( ${ }^{*} p<0.01$ vs all other groups, one-way ANOVA).

compliance in normocapnic $\mathrm{KO}$ mice appears slightly less than in wild-type mice (figure 6A,B). This may be due to higher constitutive levels of other protective mechanisms (eg, NRF2 responsive antioxidant genes; figure 9) as a compensatory mechanism in $\mathrm{KO}$ animals which have very low levels of $\alpha$-tocopherol.

$\alpha$ TTP is a cytosolic protein that is most highly expressed in hepatocytes, where it traffics $\alpha$-tocopherol and, with lower affinity, other forms of vitamin E, from endosomes to the plasma membrane in exchange for PIP2; this promotes $\alpha$-tocopherol secretion into the bloodstream, bound to lipoprotein particles. ${ }^{19}$ Expression of $\alpha$ TTP has been described outside the liver (eg, brain, lung, prostate, placenta, retina and kidney), and while information about its non-hepatic roles is limited, some of the roles seem heterogeneous. In contrast to $\alpha$-tocopherol efflux in hepatocytes, ${ }^{20}$ overexpression in prostate 

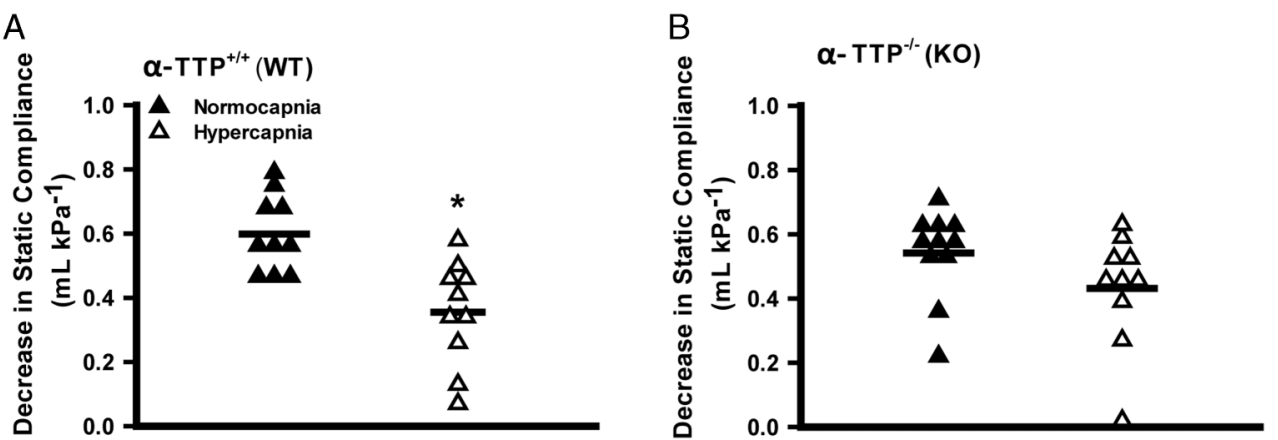

Figure 6 The $\alpha$-tocopherol transferase protein $(\alpha \mathrm{TTP})$ gene is required for $\mathrm{CO}_{2}$-mediated protection of compliance in murine ventilator induced lung injury. High-stretch (injurious) mechanical ventilation results in decreased static compliance in $\alpha \mathrm{TTP}^{+/+}$and $\alpha \mathrm{TTP}^{-1-}$ mice. Hypercapnia is protective (ie, reduces the injury) in $\alpha \operatorname{TTP}^{+/+}(\mathrm{A})$, but not in $\alpha \mathrm{TTP}^{-/-}$(B) mice ( ${ }^{*} \mathrm{p}=0.001, \mathrm{t}$ test). KO, knockout; WT, wild type.

cells promotes accumulation of $\alpha$-tocopherol, ${ }^{21}$ indicating tissue-specific functions. In addition, human mutations in the $\alpha$ TTP gene cause progressive ataxia and vitamin E deficiency ('AVED').

Surprisingly, we did not demonstrate a role for $\alpha$ TTP against oxidative stress in VILI, in terms of superoxide (figure 10A) or lipid peroxidation (ie, 8-Iso PGF2 $\alpha$, see online supplementary table S4). This may be because of higher constitutive NRF2 antioxidant expression in $\alpha \mathrm{TTP}$ colony mice versus $\mathrm{C} 57 \mathrm{BL} / 6 \mathrm{~J}$ mice (figure 9C, D). Indeed, an increase in constitutive expression of NRF-2-responsive genes in $\alpha$ TTP KO mice has been previously noted $^{22}$ and may reflect an adaptation to lower levels of $\alpha$-tocopherol. Our observation that WT sibs also display elevation may be due to copy insufficiency during development in a heterozygote mother. It is possible that induction of $\alpha$ TTP by hypercapnia in other strains $(\mathrm{eg}, \mathrm{C} 57 \mathrm{Bl} / 6 \mathrm{~J}$ ) or species reduces oxidative stress.

There is nevertheless considerable evidence that vitamin $\mathrm{E}$ (including $\alpha, \beta, \gamma$ and $\delta$ tocopherols and tocotrienols) modulates the innate immune response in lung. $\alpha$-Tocopherol suppresses inflammatory responses and lipopolysaccharide (LPS)-induced oxidative injury in lung epithelial cells, ${ }^{23}$ and multiple formulations of vitamin E protect in lung injury models. ${ }^{24}$ For example, in rodent models of LPS-induced lung injury, intraperitoneal $\alpha$-tocopherol decreased lung oedema and neutrophil transmigration without affecting cytokine levels or NFкB activation, ${ }^{25}$ while enteral $\gamma$-tocopherol (a more powerful antioxidant than $\alpha$-tocopherol) decreased neutrophils and the key inflammatory mediators MIP-2, CINC-1 and $\mathrm{PGE}_{2}{ }^{26}$ A small human study demonstrated that oral $\gamma$-tocopherol reduced sputum neutrophil numbers following intranasal LPS. ${ }^{27}$

However, important gaps exist in our understanding of the protective effects of $\alpha$-tocopherol: supplementation protects against lung injury in murine bacterial pneumonia (Streptococcus pneumoniae), reducing mortality, bacterial load, and neutrophil transepithelial migration. ${ }^{28}$ In addition, while $\alpha$-tocopherol protects against hyperoxic lung injury through antioxidant mechanisms, ${ }^{29}$ the mechanisms of protection in other lung injury (eg, sepsis) is unclear.

Most clinical studies of $\alpha$-tocopherol supplementation show minimal or no benefit in patients who have adequate dietary intake, ${ }^{24}$ including the critically ill. ${ }^{30}$ An important limitation not addressed in other studies is intracellular accumulation and trafficking of $\alpha$-tocopherol in non-hepatic tissue. Increased TTP expression could overcome such a limitation, although achieving increased expression would be a challenge. Alternatively, bypassing limited endogenous transport mechanisms by direct application of tocopherols, such as aerosolisation or incorporation into surfactant, might enhance their effects. In addition, recent data indicate that metabolites, for example, $\gamma$-tocopherol or tocotrienols, may prove more efficacious. $^{24}$

Beyond neutralisation of oxygen-derived or nitrogenderived radicals, vitamin $\mathrm{E}$ can regulate eicosanoid metabolism. ${ }^{17}$ Eicosanoids, including prostaglandins, thromboxanes, leukotrienes and HETEs, are an important network of signalling molecules that regulate inflammatory responses in critical illness. For example, cyclic stretch of lung epithelial cells (mimicking dyspnoea or mechanical ventilation) activates $\mathrm{CPLA}_{2},{ }^{31}$ thereby providing free arachidonic acid for eicosanoid biosynthesis. $\alpha$-Tocopherol modulates eicosanoid synthesis through multiple means, such as preventing the oxidation of lipid precursors, modulating mediators derived from 12-LOX and 12/15-LOX, ${ }^{32}$ and specific inhibition of 5-LOX. ${ }^{17}$ Among a panel of arachidonate products, we identified significant reduction in LTB4 and CysLTs (and a trend to decreased 5-HETE) resulting from hypercapnic induction of $\alpha$ TTP. Hypercapnia did not influence levels of other eicosanoids, including COX-derived prostaglandins, products of other LOX enzymes (12-HETE or 15-HETE) or non-enzymatic oxidation products of arachidonic acid (9-HETE, 11-HETE) (see online supplementary table S4). Together these data indicate that in our model, hypercapnia increased expression of $\alpha \mathrm{TTP}$; this increased accumulation and/or trafficking of $\alpha$-tocopherol, leading in turn to specific inhibition of 5-LOX, and lower levels of leukotrienes.

Such lowering of leukotriene levels is a plausible downstream mechanism for protection against lung injury in the current experiments. LTB4 is a potent PMN chemoattractant, providing a key signal for transmigration into the airway mediated by specific G-protein coupled receptors (BLT1, BLT2), and CysLTs increase vascular permeability and modulate vascular smooth muscle tone via CysLT1 and CysLT2 receptors. A small clinical study has demonstrated that plasma levels of leukotrienes were elevated in patients with ARDS early in their illness, and early LTB4 levels predicted mortality from ARDS. ${ }^{33}$

In other models of lung injury, antagonism of 5-LOX is protective; for example, pharmacological inhibition and gene knockout of 5 -LOX protect against murine VILI, ${ }^{18}$ and in murine sepsis $\mathrm{KO}$ of the 5-LOX gene (or inhibition of the enzyme) provided more protection than use of leukotriene receptor antagonists (eg, Montelukast). ${ }^{34}$ Antagonism of LTB4 is also effective in lung injury caused by haemorrhagic shock ${ }^{35}$ or in carrageenan-induced pleurisy. ${ }^{36}$ 

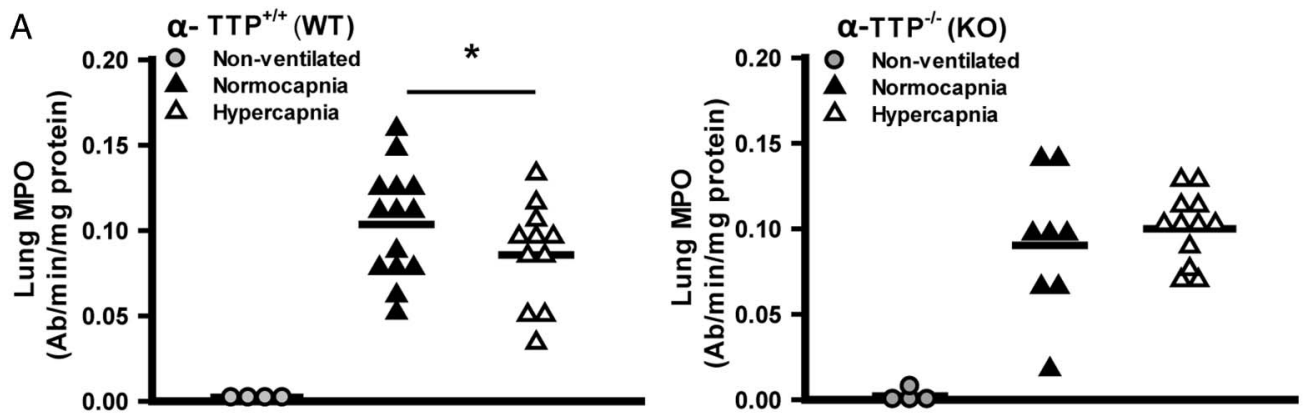

B
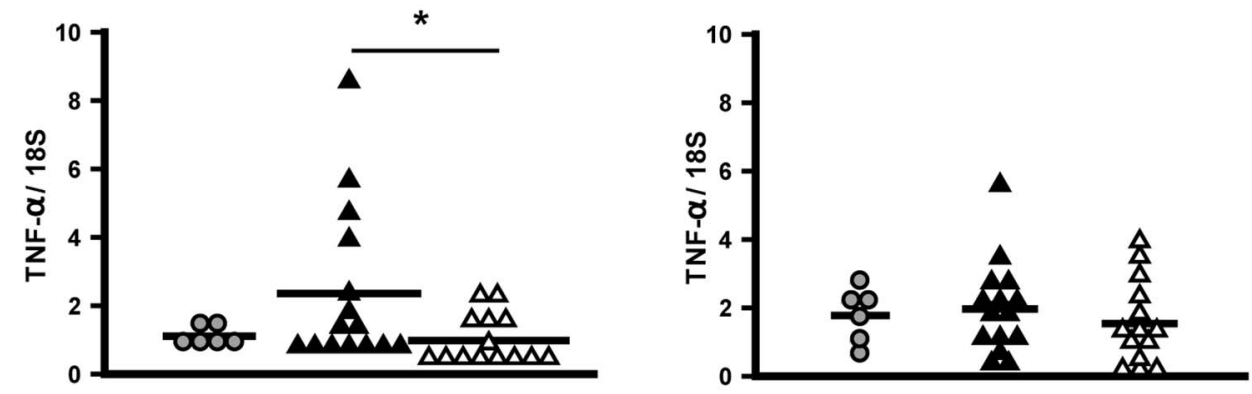

C
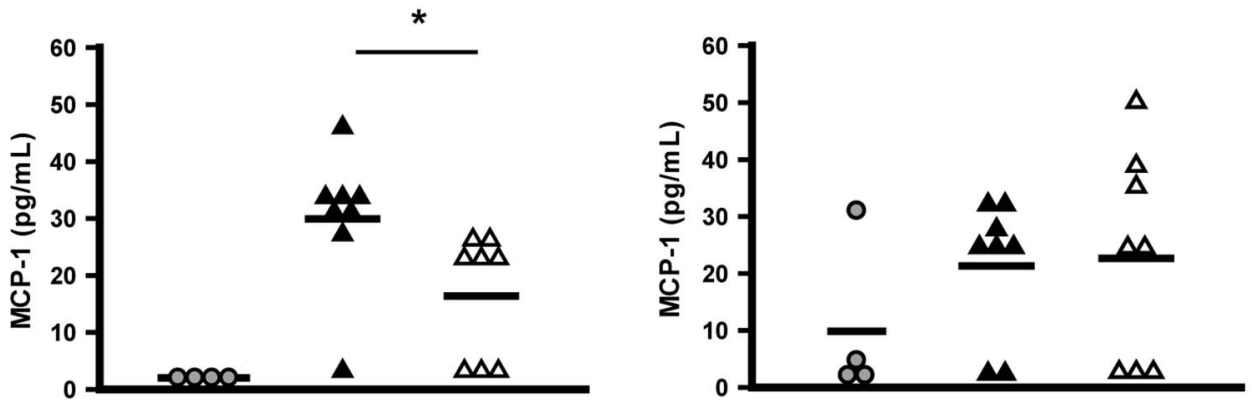

D
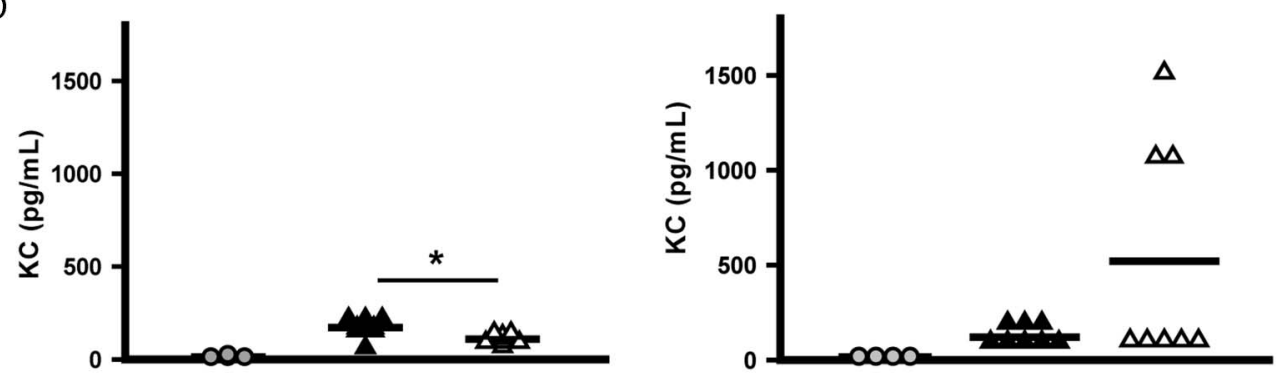

$\mathrm{E}$
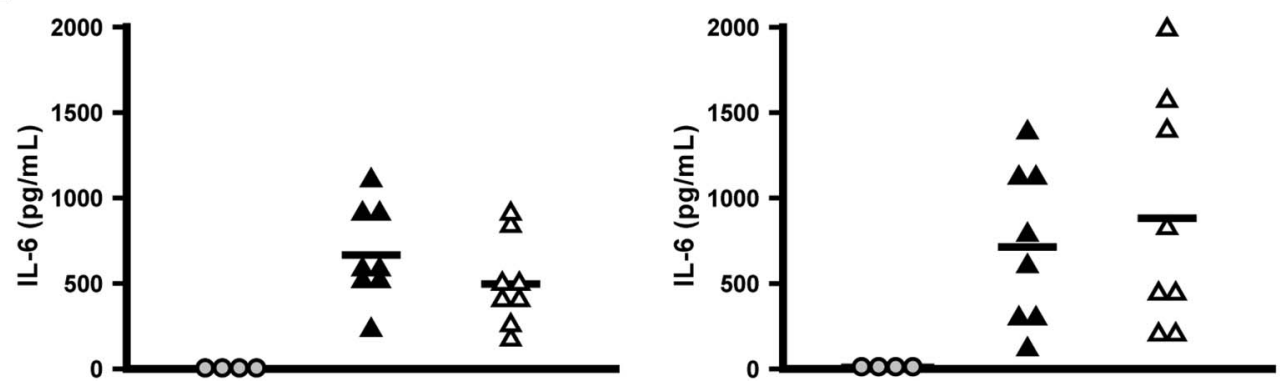

Figure $7 \quad \mathrm{CO}_{2}$-mediated protection and impact of $\alpha$-tocopherol transferase protein $(\alpha \mathrm{TTP})$ on biochemical injury markers. Tissue levels of myeloperoxidase (MPO) activity (A) and TNF $\alpha$ mRNA (B) are significantly less after 3 hours of injurious ventilation with hypercapnia versus normocapnia (ie, hypercapnia protective) in $\alpha \mathrm{TTP}^{+/+}$(left panels) mice, but not in $\alpha \mathrm{TTP}^{-/-}$(right panels) mice. Trends for these patterns (hypercapnic protection in $\alpha \mathrm{TTP}^{+/+}$, not in $\alpha \mathrm{TTP}^{-l-}$ ) were preserved for bronchoalveolar lavage levels of monocyte chemoattractant protein 1 (MCP-1; C), keratinocyte chemoattractant (KC; D), and interleukin 6 (IL-6; E) ( ${ }^{*} \mathrm{p}<0.05$ vs normocapnia, $t$ test). Data from non-ventilated mice are presented for illustrative purposes but excluded from statistical analysis. KO, knockout; WT, wild type. 

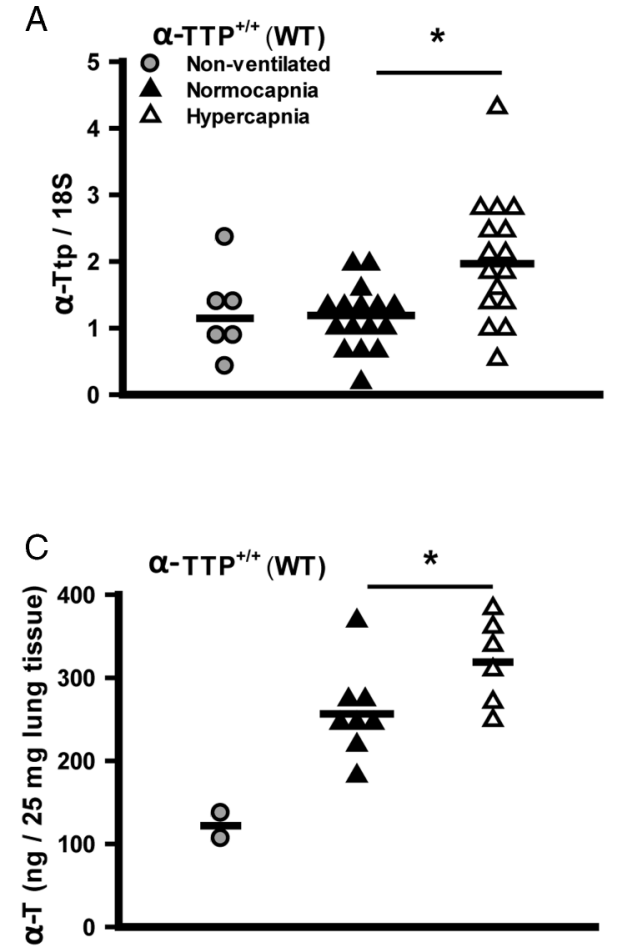

B

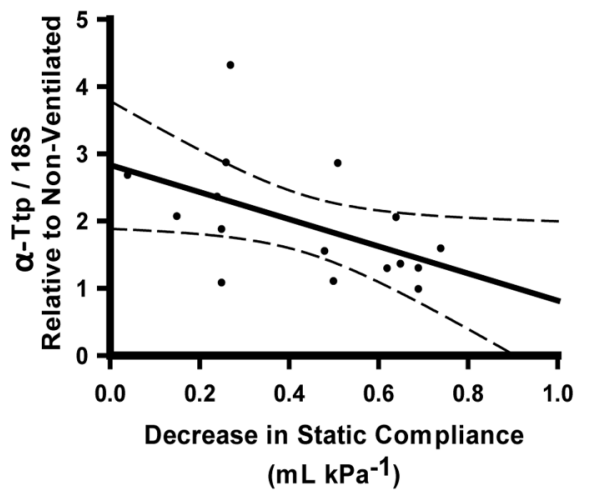

D

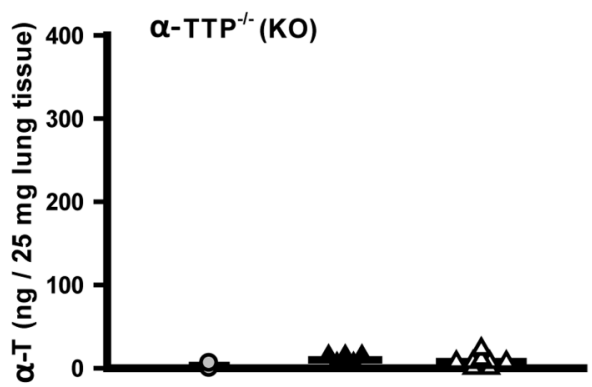

Figure 8 Effects of mechanical ventilation and hypercapnia on lung $\alpha$-tocopherol transferase protein ( $\alpha$ TTP) mRNA expression and $\alpha$-tocopherol levels. Hypercapnia induced expression of $\alpha$ TTP mRNA in lung tissue of $\alpha \mathrm{TTP}^{+/+}$mice following high-stretch ventilation (Mann-Whitney) (A). Linear regression demonstrates the correlation between expression of $\alpha \mathrm{TTP}$ mRNA and $\mathrm{CO}_{2}$ protective effect (regression expressed $\pm 95 \% \mathrm{Cls}$; $\mathrm{R}=-0.50$, $\mathrm{p}<0.05)(B)$. Lung tissue $\alpha$-tocopherol $(\alpha-\mathrm{T})$ levels in $\alpha \mathrm{TTP}^{+/+}$mice are increased by hypercapnia during ventilation (t test) (C), and are 20-50 fold less in $\alpha \mathrm{TTP}^{-1-}$ mice (D) ( ${ }^{*} \mathrm{p}<0.05$ vs normocapnia). Data from $(\mathrm{n}=2-4)$ non-ventilated mice are presented for illustrative purposes but excluded from statistical analysis. KO, knockout; WT, wild type.

Figure 9 Antioxidant response pathway in $\alpha$-tocopherol transferase protein $\left(\alpha \mathrm{TTP}^{+/+}\right)$and $\alpha \mathrm{TTP}^{-l-}$ murine model of ventilator-induced lung injury, effect of hypercapnia. $\alpha$ TTP $^{+/+}$ and $\alpha \mathrm{TTP}^{-l-}$ mice expressed higher constitutive levels of mRNA for NRF2 target genes heme oxygenase (HMOX1) (A) and glutathione-S-transferase (GSTA1) (B) than $C 57 \mathrm{BL} / 6 \mathrm{~J}$ mice $(\S p<0.05$ vs C57BL/6J, ANOVA on RANKS). Expression of HMOX1 (C) and GSTA1 (D) during injurious mechanical ventilation is similar in $\alpha \mathrm{TTP}^{+/+}$and $\alpha \mathrm{TTP}^{-l-}$ mouse lungs. In

non-ventilated mice, constitutive levels of HMOX1 and GSTA1 were higher in $\alpha \mathrm{TTP}^{-1-}$ versus $\alpha \mathrm{TTP}^{+/+}$mice $\left({ }^{*} \mathrm{p}<0.01\right.$ vs $\alpha \mathrm{TTP}^{+/+}$, two-way ANOVA). Both genes were similarly induced by VILI and this effect was abrogated by hypercapnia $(t p<0.05$ vs all other ventilation groups). KO, knockout; $\mathrm{WT}$, wild type.

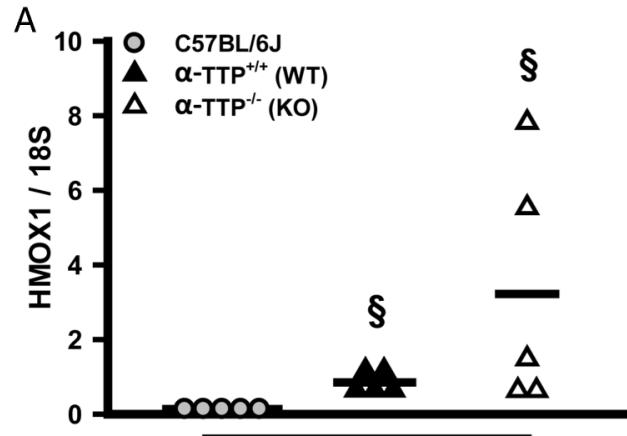

Non-ventilated

C

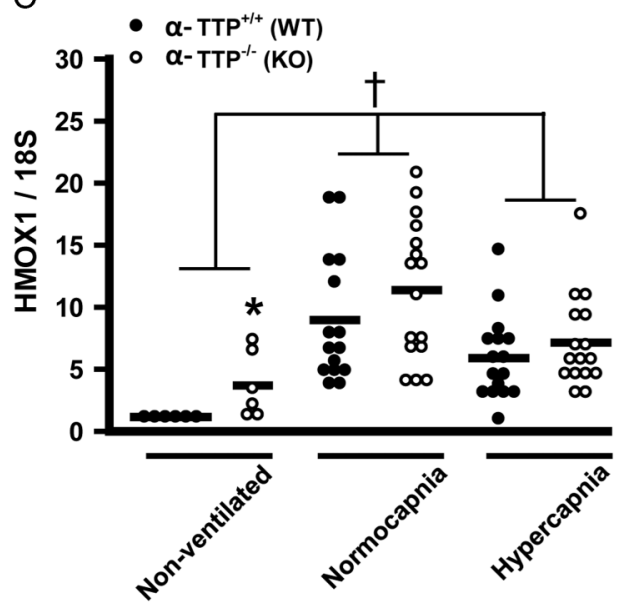

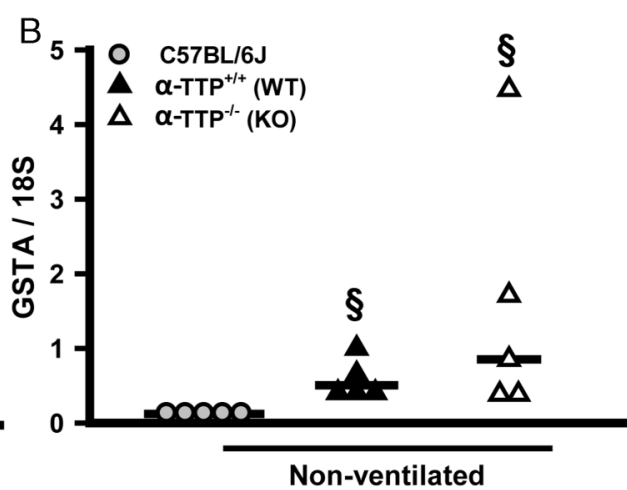

D

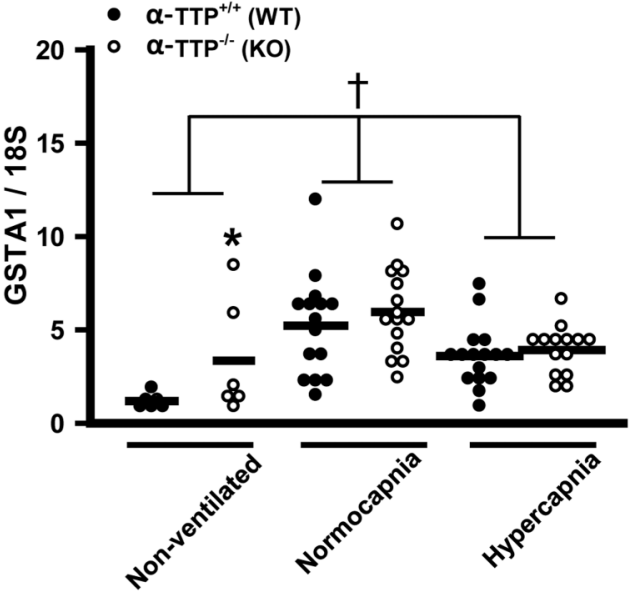



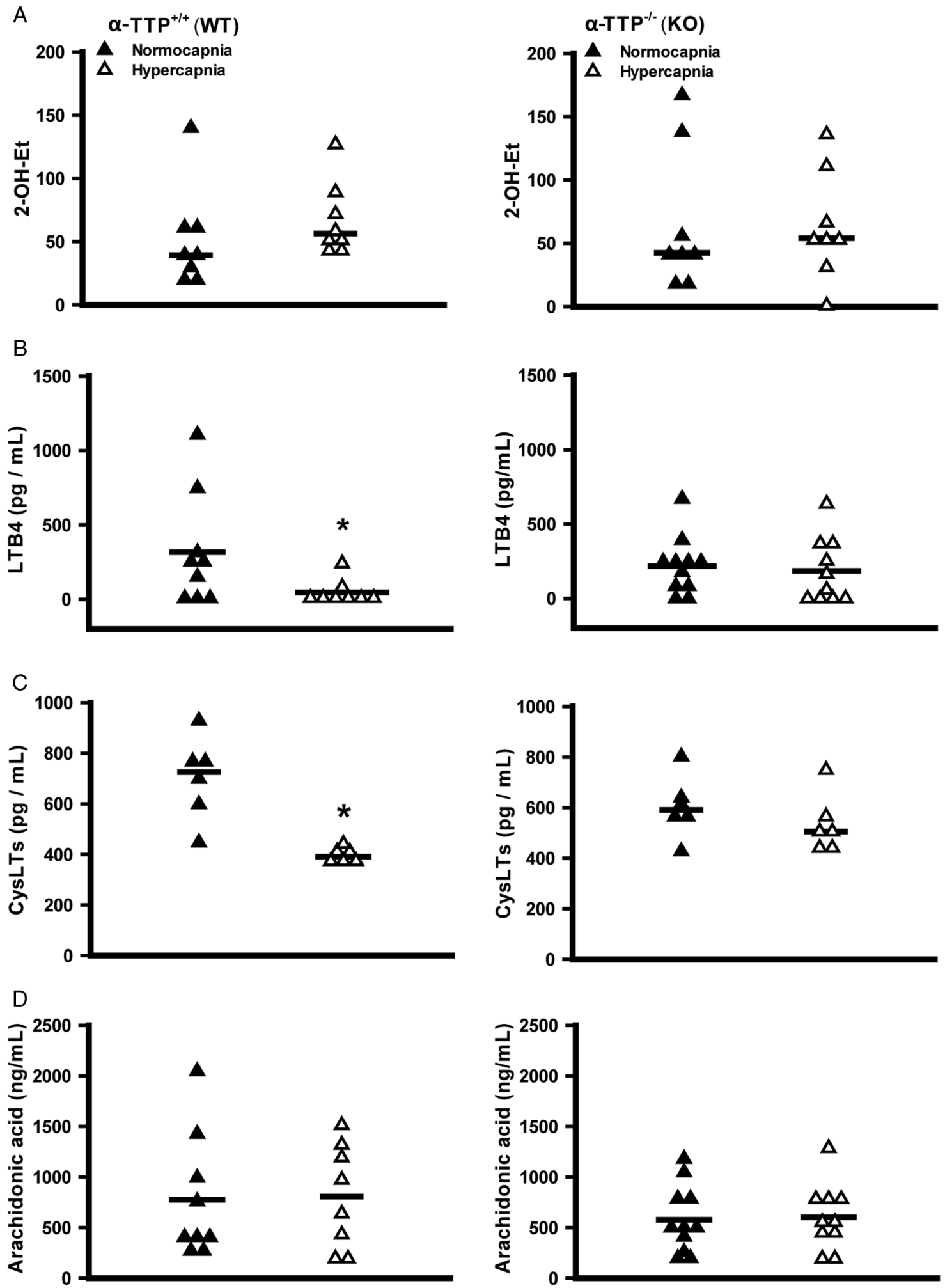

Figure 10 Hypercapnia-induced $\alpha$ tocopherol transfer protein ( $\alpha \mathrm{TTP})$ attenuates leukotriene synthesis, not reactive oxygen species production, in murine ventilator-induced lung injury. Relative levels of superoxide in $\alpha \mathrm{TT}^{+/+}$and $\alpha \mathrm{TTP}^{-1-}$ mouse lungs were measured as 2-hydroxy-ethidium (2-OH-Et, arbitrary units) in mice injected with hydroethidine and subjected to 3 hours of injurious ventilation (A). There was no significant difference in superoxide levels between normocapnia and hypercapnia in $\alpha \mathrm{TTP}^{-1-}$ or $\alpha \mathrm{TTP}^{+++}$animals (Mann-Whitney). Hypercapnia suppressed levels of leukotriene B4 (LTB4, t test) and cysteinyl leukotrienes (CysLTs, Mann-Whitney) in the bronchoalveolar fluid from $\alpha$ TTP $^{+/+}$mice subjected to injurious ventilation, but had no effect on leukotriene levels in $\alpha T_{T P}^{-l-}$ mice (B and C). Hypercapnia did not alter arachidonic acid levels in bronchoalveolar fluid from mice of either genotype (D) ( ${ }^{*} p<0.05$ vs normocapnia). KO, knockout; WT, wild type. 
Despite preclinical success in experimental lung injury, caution is required in therapeutic targeting of leukotrienes. Many patients with lung injury have concomitant sepsis, and reduced leukotriene function could impair pathogen clearance. In addition, 5-LOX inhibition could divert arachidonic acid via alternative pathways (eg, COX), thereby altering the balance of eicosanoid signalling; in later stages this could impair production of the pro-resolving 5-LOX product, lipoxin A4. Targeting leukotriene receptors is effective in lung injury models. ${ }^{18} 37$ However, the high affinity LTB4 receptor, known as BLT1, is also a receptor for Resolvin E1, a pro-resolving mediator which enhances resolution of lung injury. Leukotriene A4 hydrolase (LTA4H), the enzyme that converts LTA4 (the unstable direct product of 5-LOX) into LTB4, can be targeted by several antagonists (eg, SC57461A, JNJ-26993235, or ARM1) ${ }^{38}$ to reduce LTB4 synthesis, while protecting pro-resolving mediators, but optimal blockade may also require CysLT inhibition.

There are important limitations to this study. Only male mice were used and impact of gender is unknown. We have been unable to identify the specific cell types in the lung that express $\alpha$ TTP due to a lack of suitable antibodies for immunohistochemistry. It is unclear whether the protective effects of $\alpha$ TTP $(\approx 20 \%$ increased expression) result from the modest increase across all lung tissue, large changes in a subset of cells, or from $\alpha$ TTP's trafficking effect to particular subcellular locations. We have not tested whether $\alpha$ TTP has a protective role in other models of lung injury, ${ }^{34}$ and did not explore the mechanism by which hypercapnia upregulates $\alpha$ TTP expression. Finally, the $\alpha$ TTP gene promoter is not yet well characterised. Animal experiments investigating effects of dietary $\alpha$-tocopherol and oxidative stress on hepatic $\alpha$ TTP expression in vivo provided conflicting data. ${ }^{39}$ However, immortalised hepatocytes upregulate $\alpha$ TTP in response to peroxide, hypoxia and agonists of nuclear receptors peroxisome proliferator-activated receptor $\alpha$ and retinoid X receptor; ${ }^{40}$ and the $\alpha \mathrm{TTP}$ gene is a direct target for transactivation by the liver $\mathrm{X}$ receptor, a transcription factor that modulates cholesterol metabolism and lipid biosynthesis. ${ }^{39}$

While deliberate induction of hypercapnia remains an experimental intervention, ${ }^{2}$ so-called 'permissive hypercapnia' is widely accepted in mechanically ventilated patients; however, the case for net harm versus benefit in permissive hypercapnia is uncertain. Nevertheless, hypercapnia is an important tool in laboratory studies such as this to elucidate relevant, previously unsuspected pathways, such as upregulation of $\alpha$ TTP as shown here, or discovering the role of ADAM- $17 .^{6}$ Although the role of $\alpha$ TTP in lung tissue has received little attention, our data showing induction in multiple mouse models suggest broad applicability, and the correlation with lung protection is evidence of an induced, protective pathway. Targeted interventions such as aerosolisation of vitamin $\mathrm{E}$ formulations into the lung, or specific inhibition of LTA4H, are related to new approaches to protecting the injured lung.

Acknowledgements This study was supported by Canadian Institutes of Health Research Operating Grant to B.P.K. (FRN 69006). BAL mediator measurements were performed by the Analytical Facility for Bioactive Molecules of The Centre for the Study of Complex Childhood Diseases, The Hospital for Sick Children, Toronto, Canada.

Contributors GO conceived the study, conducted the study, and analysed the data. DE, HA and HH participated in study design, conducted experiments, analysed data. HB, MP and BPK participated in study design, data analysis and interpretation. All authors participated in drafting or critically revising the manuscript and approved the final version.

Funding Institute of Circulatory and Respiratory Health (FRN 69006).

Competing interests None declared.
Provenance and peer review Not commissioned; externally peer reviewed.

Data sharing statement Primary microarray datasets are accessible through $\mathrm{NCB}$ GEO (series accession number GSE86229).

\section{REFERENCES}

1 ARDS Network. Ventilation with lower tidal volumes as compared with traditional tidal volumes for acute lung injury and the acute respiratory distress syndrome. The Acute Respiratory Distress Syndrome Network. N Engl J Med 2000;342:1301-8.

2 Masterson C, Otulakowski G, Kavanagh BP. Hypercapnia: clinical relevance and mechanisms of action. Curr Opin Crit Care 2015;21:7-12.

3 Laffey JG, Tanaka M, Engelberts $D$, et al. Therapeutic hypercapnia reduces pulmonary and systemic injury following in vivo lung reperfusion. Am J Respir Crit Care Med 2000;162:2287-94.

4 Ni Chonghaile M, Higgins BD, Costello JF, et al. Hypercapnic acidosis attenuates severe acute bacterial pneumonia-induced lung injury by a neutrophil-independent mechanism. Crit Care Med 2008;36:3135-44.

5 Peltekova V, Engelberts D, Otulakowski G, et al. Hypercapnic acidosis in ventilator-induced lung injury. Intensive Care Med 2010;36:869-78.

6 Otulakowski G, Engelberts D, Gusarova GA, et al. Hypercapnia attenuates ventilator-induced lung injury via a disintegrin and metalloprotease-17. J Physiol (Lond) 2014;592:4507-21.

7 Vadász I, Dada LA, Briva A, et al. AMP-activated protein kinase regulates CO2-induced alveolar epithelial dysfunction in rats and human cells by promoting $\mathrm{Na}, \mathrm{K}-\mathrm{ATP}$ ase endocytosis. J Clin Invest 2008;118:752-62.

8 Takeshita K, Suzuki Y, Nishio K, et al. Hypercapnic acidosis attenuates endotoxin-induced nuclear factor-\{kappa\}B activation. Am J Respir Cell Mol Biol 2003;29:124-32

9 Wurfel MM. Microarray-based analysis of ventilator-induced lung injury. Proc Am Thorac Soc 2007:4:77-84.

10 Li G, Zhou D, Vicencio AG, et al. Effect of carbon dioxide on neonatal mouse lung: a genomic approach. J App/ Physiol 2006;101:1556-64.

11 Cummins EP, Keogh CE. Respiratory gases and the regulation of transcription. Exp Physiol 2016;101:986-1002.

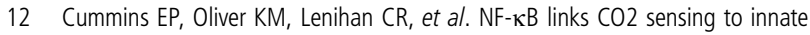
immunity and inflammation in mammalian cells. J Immunol 2010;185:4439-45.

13 Selfridge AC, Cavadas MA, Scholz CC, et al. Hypercapnia suppresses the HIF-dependent adaptive response to hypoxia. J Biol Chem 2016;291:11800-8.

14 Townsend PD, Holliday PM, Fenyk S, et al. Stimulation of mammalian G-protein-responsive adenylyl cyclases by carbon dioxide. J Biol Chem 2009:284:784-91.

15 Jaitovich A, Angulo M, Lecuona E, et al. High CO2 levels cause skeletal muscle atrophy via AMP-activated kinase (AMPK), FoxO3a protein, and muscle-specific Ring finger protein 1 (MuRF1). J Biol Chem 2015;290:9183-94.

16 Papaiahgari S, Yerrapureddy A, Reddy SR, et al. Genetic and pharmacologic evidence links oxidative stress to ventilator-induced lung injury in mice. Am J Respir Crit Care Med 2007;176:1222-35.

17 Jiang Z, Yin X, Jiang Q. Natural forms of vitamin E and 13'-carboxychromanol, a long-chain vitamin $\mathrm{E}$ metabolite, inhibit leukotriene generation from stimulated neutrophils by blocking calcium influx and suppressing 5-lipoxygenase activity, respectively. J Immunol 2011;186:1173-9.

18 Caironi $\mathrm{P}$, Ichinose $\mathrm{F}$, Liu $\mathrm{R}$, et al. 5-Lipoxygenase deficiency prevents respiratory failure during ventilator-induced lung injury. Am J Respir Crit Care Med 2005; 172:334-43.

19 Kono N, Arai H. Intracellular transport of fat-soluble vitamins A and E. Traffic 2015; 16:19-34.

20 Qian J, Morley S, Wilson K, et al. Intracellular trafficking of vitamin E in hepatocytes: the role of tocopherol transfer protein. J Lipid Res 2005;46:2072-82.

21 Morley S, Thakur V, Danielpour D, et al. Tocopherol transfer protein sensitizes prostate cancer cells to vitamin E. J Biol Chem 2010;285:35578-89.

22 Gohil K, Oommen S, Vasu VT, et al. Tocopherol transfer protein deficiency modifies nuclear receptor transcriptional networks in lungs: modulation by cigarette smoke in vivo. Mol Aspects Med 2007;28:453-80.

23 Ekstrand-Hammarström B, Osterlund C, Lilliehöök B, et al. Vitamin E down-modulates mitogen-activated protein kinases, nuclear factor-kappaB and inflammatory responses in lung epithelial cells. Clin Exp Immunol 2007;147:359-69.

24 Jiang Q. Natural forms of vitamin E: metabolism, antioxidant, and anti-inflammatory activities and their role in disease prevention and therapy. Free Radic Biol Med 2014;72:76-90

25 Rocksén D, Ekstrand-Hammarström B, Johansson L, et al. Vitamin E reduces transendothelial migration of neutrophils and prevents lung injury in endotoxin-induced airway inflammation. Am J Respir Cell Mol Biol 2003;28:199-207.

26 Wagner JG, Birmingham NP, Jackson-Humbles D, et al. Supplementation with gamma-tocopherol attenuates endotoxin-induced airway neutrophil and mucous cell responses in rats. Free Radic Biol Med 2014;68C:101-9.

27 Hernandez ML, Wagner JG, Kala A, et al. Vitamin E, $\gamma$-tocopherol, reduces airway neutrophil recruitment after inhaled endotoxin challenge in rats and in healthy volunteers. Free Radic Biol Med 2013;60:56-62. 
28 Bou Ghanem EN, Clark S, Du X, et al. The $\alpha$-tocopherol form of vitamin E reverses age-associated susceptibility to streptococcus pneumoniae lung infection by modulating pulmonary neutrophil recruitment. J Immunol 2015;194:1090-9.

29 Yamaoka S, Kim HS, Ogihara T, et al. Severe vitamin E deficiency exacerbates acute hyperoxic lung injury associated with increased oxidative stress and inflammation. Free Radic Res 2008;42:602-12.

30 Howe KP, Clochesy JM, Goldstein LS, et al. Mechanical ventilation antioxidant trial. Am J Crit Care 2015:24:440-5.

31 Copland IB, Reynaud D, Pace-Asciak C, et al. Mechanotransduction of stretch-induced prostanoid release by fetal lung epithelial cells. Am J Physiol Lung Cell Mol Physiol 2006;291:L487-95.

32 Lebold KM, Traber MG. Interactions between $\alpha$-tocopherol, polyunsaturated fatty acids, and lipoxygenases during embryogenesis. Free Radic Biol Med 2014;66:13-19.

33 Amat M, Barcons M, Mancebo J, et al. Evolution of leukotriene B4, peptide leukotrienes, and interleukin-8 plasma concentrations in patients at risk of acute respiratory distress syndrome and with acute respiratory distress syndrome: mortality prognostic study. Crit Care Med 2000;28:57-62.
34 Monteiro AP, Soledade E, Pinheiro CS, et al. Pivotal role of the 5-lipoxygenase pathway in lung injury after experimental sepsis. Am J Respir Cell Mol Biol 2014; 50:87-95.

35 Eun JC, Moore EE, Mauchley DC, et al. The 5-lipoxygenase pathway is required for acute lung injury following hemorrhagic shock. Shock 2012;37:599-604.

36 Rossi A, Pergola C, Koeberle A, et al. The 5-lipoxygenase inhibitor, zileuton, suppresses prostaglandin biosynthesis by inhibition of arachidonic acid release in macrophages. Br J Pharmacol 2010;161:555-70.

37 Li XJ, Fu HY, Yi WJ, et al. Dual role of leukotriene B4 receptor type 1 in experimental sepsis. J Surg Res 2015;193:902-8.

38 Stsiapanava A, Olsson U, Wan M, et al. Binding of Pro-Gly-Pro at the active site of leukotriene A4 hydrolase/aminopeptidase and development of an epoxide hydrolase selective inhibitor. Proc Natl Acad Sci USA 2014;111:4227-32.

39 Koh M, Takitani K, Miyazaki H, et al. Liver X receptor up-regulates $\alpha$-tocopherol transfer protein expression and $\alpha$-tocopherol status. J Nutr Biochem 2013;24:2158-67.

40 Ulatowski L, Dreussi C, Noy N, et al. Expression of the $\alpha$-tocopherol transfer protein gene is regulated by oxidative stress and common single-nucleotide polymorphisms. Free Radic Biol Med 2012;53:2318-26. 